\title{
LA SALUD EN EL PERÚ
}

\author{
HEALTH IN PERÚ
}

Javier Arias-Stella ${ }^{1, a}$

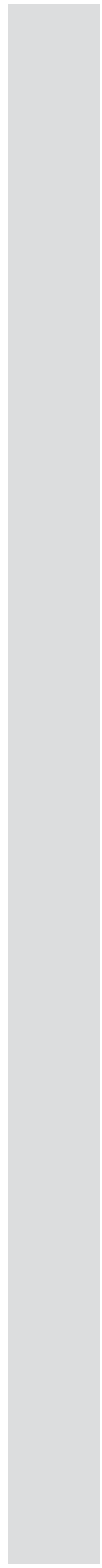

La Academia Nacional de Medicina y el Instituto Nacional de Salud han programado y ejecutado un ciclo de conferencias conjuntas sobre temas de interés de salud, a publicarse en la Revista Peruana de Medicina Experimental y Salud Pública. Dentro del marco de este programa debo introducir el tema "La Salud Pública en el siglo XXI".

La historia de la evolución de la salud en el Perú es la historia de la inestabilidad política, económica y administrativa, que, sin lograr superar las inequidades existentes desde la colonia, ha intentado, sucesivamente, mejorar racionalmente las condiciones sanitarias de la población peruana. El estudio de Carlos Bustíos subraya cómo es que en este esfuerzo se han formalizado cinco modelos organizativos del sistema oficial de salud, y cómo estos respondieron a la correlación de fuerzas económico-sociales y políticas, conservadoras o progresistas, predominantes en cada etapa. Entrados al siglo XXI se ha logrado mantener un manejo equilibrado de la macroeconomía, lo que ha estimulado el anhelo de alcanzar más altas tasas de desarrollo. La participación de economistas en la conducción de la gestión social se ha hecho más evidente y, por ende, la presencia de epidemiólogos y planificadores en la salud pública. En el campo de la Salud Pública internacional las propuestas del Banco Mundial han desplazado a la OMS.

Si bien el derecho universal al cuidado de la salud está institucionalizado jurídicamente, lograrlo será una tarea siempre difícil en el Perú. Bustíos piensa que para diseñar un nuevo sistema oficial de salud que tenga la posibilidad de plasmarse, tendríamos que haber llegado a una situación sociohistórica distinta. Un grado de convergencia entre las fuerzas políticas, hoy, lamentablemente, todavía intolerantes, que permitiera un auténtico acuerdo nacional con los mejores argumentos científicos, tecnológicos, jurídico-políticos y ético-morales, en un debate democrático.

Francisco Sánchez-Moreno hace un resumen sobre el sistema nacional de salud en el Perú, señalando el avance que significó la creación del Sistema Nacional de Servicios de Salud en 1978, antes de las reformas de los sistemas de salud en Chile (1980), Brasil (1990), Colombia (1993) y Ecuador (2008). Considera que, habiendo en el Perú condiciones macroeconómicas para lograr un mejor nivel en Salud y aseguramiento social, se tiene que asumir la responsabilidad de realizar un proceso exitoso de reforma y desarrollo ${ }^{(1)}$. El objetivo por alcanzar es el derecho fundamental de todos, al cuidado integral de la Salud y que debería ser responsabilidad general en el proceso electoral del 2016. A través de la Academia Peruana de Salud, Sánchez- Moreno propone que se organicen como Nación dos foros internacionales sobre temas cruciales:

a) Evaluación del Sistema Nacional de Salud.

b) Financiamiento contributivo e impositivo del aseguramiento social universal en salud.

El Proyecto de Ley de Política de Estado en Salud debe ser concertado con la totalidad de partidos políticos en el proceso electoral nacional del 2016 y formulado como base sustentable esencial de una verdadera reforma peruana en salud a mediano y largo plazo. Los elementos cardinales del proyecto de Ley son:

I) Vigencia del derecho fundamental a la Salud con acceso a la atención integral.

II) Políticas nacionales principales para el desarrollo moderno del sistema nacional de salud, el aseguramiento social universal, los recursos humanos de salud y los nuevos conocimientos.

\footnotetext{
Academia Nacional de Medicina. Lima, Perú

Médico patólogo

Recibido: : 12-11-14 Aprobado: 19-11-14
}

Citar como: Arias-Stella J. La salud en el Perú [editorial]. Rev Peru Med Exp Salud Publica. 2014;31(4):621-2. 
Los doctores José Gómez y Mariana Faría analizan los sistemas de salud en América del Sur, sus antecedentes histórico-políticos y los avances a partir de las reformas en las últimas tres décadas. Discuten los tres modelos paradigmáticos de reforma y los contrastes entre cobertura universal y los sistemas universales. Subrayan sus fortalezas y debilidades y las oportunidades y desafíos que se presentan en el momento actual en UNASUR ${ }^{(2)}$. Si bien el derecho a la salud está garantizado constitucionalmente en la mayoría de los países de UNASUR, en ninguno de ellos los modelos empleados han logrado una cobertura poblacional del $100 \%$.

Ruben Darío Gómez Arias comenta sobre la reforma de salud adoptada en Colombia en 1993, siguiendo los lineamientos del consejo de Washington y del Banco Mundial. Se desmontó el sistema estatal, se incrementó las finanzas del sector y se enfatizó la administración del sistema al sector privado. Después de 20 años el modelo colombiano ha evidenciado serias fallas y actualmente es objeto de controversias ${ }^{(3)}$.

La reforma de salud en el Ecuador es un proceso muy reciente y ha tenido importantes avances por la decisión política para tratar de profundizarlo. Su sostenibilidad podrá ser garantizada, solamente, cuando se convierta en una política de estado ${ }^{(4)}$.

La doctora Susana Ramírez estudia el cambio que propuso el estado boliviano a partir de la subida al poder de Evo Morales, y hace una reflexión sobre cómo la interculturalidad, entendida como el camino para mejorar la salud de la población boliviana, no está contribuyendo a la mejora de la calidad de vida y de la salud. Hasta el momento, el cambio anunciado se ha completado en transformaciones ideológicas, como el considerar la salud un derecho y no una mercancía e incorporar la ley de la medicina tradicional. Sin embargo, ese proceso no ha modificado la realidad de la inequidad social, por falta de una infraestructura de salud adecuada ${ }^{(5)}$.

Los doctores Leslie Zevallos, Valerio Salas y Luis Robles han revisado los documentos publicados por el Ministerio de Salud del Perú sobre la asociación público privada (APP), así como las normativas vigentes sobre el tema. Existen normativas sobre APP en general, pero ninguna específica sobre servicios de salud. Como parte de la reforma del sector salud en el Perú, actualmente se están convocando a varios hospitales en la modalidad de asociación público privada (APP) en salud. Médicos y servidores públicos permanecen expectantes ante estos intentos. Hay todavía preguntas sin una clara respuesta: ¿cómo se puede estructurar y supervisar las interacciones público privadas con la finalidad de evitar o hacer frente a los conflictos de interés?, ¿cómo se pueden hacer alianzas para funcionar de acuerdo con los principios de buen gobierno? Los doctores Zevallos, Salas y Robles discuten la terminología empleada para abordar el tema del concepto de concesión y el funcionamiento de una asociación público-privada y la conveniencia de una asociación privada para los servicios de salud en el Perú. Concluyen que en estos momentos no es factible medir los resultados de una asociación público privada para servicios de salud en el Perú ${ }^{(6)}$.

Conviene continuar con la investigación en este ámbito.

\section{REFERENCIAS BIBLIOGRÁFICAS}

1. Sánchez-Moreno F. El sistema nacional de salud en el Perú. Rev Peru Med Exp Salud Publica. 2014;31(4): 747-53.

2. Gomes Temporão J, Faria M. Reformas de los sistemas de salud en Sudamérica: una oportunidad para UNASUR. Rev Peru Med Exp Salud Publica. 2014;31(4): 740-6.
3. Gómez-Arias RD, Nieto E. Colombia: ¿qué ha pasado con su reforma de salud? Rev Peru Med Exp Salud Publica. 2014;31(4): 733-9.

4. Malo-Serrano M, Malo-Corral N. Reforma de salud en Ecuador: nunca más el derecho a la salud como un privilegio. Rev Peru Med Exp Salud Publica. 2014;31(4): 754-61.
5. Ramírez Hita S. Aspectos interculturales de la reforma del sistema de salud en Bolivia. Rev Peru Med Exp Salud Publica. 2014;31(4): 762-8.

6. Zevallos L, Salas V, Robles L. Asociaciones público-privadas para servicio de salud: ¿̇a solución al sistema de salud peruano? Rev Peru Med Exp Salud Publica. 2014;31(4): 769-74. 